\title{
Monitoring UF membrane performance treating surface-groundwater blends: limitations of FEEM-PARAFAC on the assessment of the organic matter role
}

\author{
M.Vera ${ }^{1,2^{*}}$, J.Martín-Alonso ${ }^{1}$, J.Mesa ${ }^{1}$, M.Granados ${ }^{3}$, J.L.Beltran ${ }^{3}$, S.Casas ${ }^{4}$, O.Gibert ${ }^{2,4}$, \\ J.L.Cortina ${ }^{2,4}$ \\ ${ }^{1}$ Aigües de Barcelona, Empresa Metropolitana de Gestió del Cicle Integral de l'Aigua, Gral. \\ Batet 1-7, 08028 Barcelona, Spain \\ ${ }^{2}$ Barcelona Research Center in Multiscale Science and Engineering, EEBE, Universitat Politècnica \\ de Catalunya (UPC) - BarcelonaTECH, c/Eduard Maristany 10-14, 08019 Barcelona, Spain \\ ${ }^{3}$ Department of Analytical Chemistry, Universitat de Barcelona, c/Martí i Franquès 1, 08028 \\ Barcelona, Spain \\ ${ }^{4}$ CETAQUA, Water Technology Center, Ctra. D’Esplugues 75, 08940 Cornellà de Llobregat, Spain \\ *mverac@aiguesdebarcelona.cat
}

\section{Abstract}

The decrease of water quantity and quality in water scarcity areas is palliated by improving water treatments with membrane technologies. System performance and efficiency, and then cost, is mainly affected by membrane fouling, which is still not well understood and controlled appropriately. In this study, the influence of content and composition of dissolved organic matter (DOM) on a membrane ultrafiltration (UF) stage from a full-scale UF stage in a drinking water treatment plant (DWTP) fed with surface water, groundwater (or blends of them) was investigated. Excitation-emission matrix (EEM) fluorescence spectroscopy coupled with parallel factor analysis (PARAFAC) was used to characterize and assess DOM changes in water samples Water streams feeding the UF stage showed high variability in DOM content and composition. FEEM-PARAFAC analysis allowed the differentiation of seven different organic components. Additionally to the characterization and monitoring of DOM in the full-scale UF stage, a bench scale UF pilot was run to experimentally correlate the impact of water quality with membrane performance. The experiments included testing synthetic solutions of model foulants 
(synthetic humic acid and bovine serum albumin) and blends of complex waters. To quantify fouling, the total fouling index (TFI) and the hydraulically irreversible fouling index (HIFI) were calculated for each filtration run. According to the results obtained, the correlation plots between the PARAFAC components and the fouling indices pointed at microbial byproducts (C1) and humic-like components (C2, C4, C5) as the ones showing higher correlations.

\section{Keywords}

Fluorescence spectroscopy; Parallel factor analysis (PARAFAC); membrane ultrafiltration; fouling indices; dissolved organic matter (DOM)

\section{1.- Introduction}

Reverse Osmosis (RO) with ultrafiltration (UF) as a pre-treatment step are proposed for drinking water purification processes as robust and flexible technologies used to improve water quality and taste by removing undesirable components such as high salinity levels, organic and inorganic micro-pollutants, or pathogens [1-3]. Advances in materials, system designs, and process combinations coupled with more stringent quality standards opened the door to affordable implementation of membranes in drinking water treatment plants (DWTP). This is the case of DWTPs located in arid and semiarid climates, where surface resources are scarce and water quality is affected by high dissolved organic matter (DOM) contents [4-5]. In this scenario, blends of surface water with groundwater resources are used to improve water quality. The main purpose of the UF stage is to protect the RO by lowering the particulate content and rejecting 
residual coagulants such as aluminum and iron. Unfortunately, in dead-end UF systems, rejected materials are inevitably accumulated on the membrane. Fouling affects membrane performance by incrementing the operational costs [6] and reducing the membrane lifetime expectancy [7]. It can be caused by DOM, the presence of microorganisms (algae, viruses, bacteria...) and particulate/colloidal matter [8-9].

Quantifying how a specific water would affect the membrane performance is indispensable. The potential of water to foul membranes is quantified with different fouling indices. Huang et al. developed the unified membrane-fouling index (UMFI) which is obtained from operation parameters (such as flux and transmembrane pressure) and present the advantage over previous indices of accounting for the membrane-specificity and the being independent of filtration scale [10]. The UMFI is convenient to quantify the fouling potential of waters at bench- and pilot-scale systems [11]. Later on, Nguyen et al. obtained the same mathematical expression, as the UMFI index, based on a resistance in-series approach and defined different fouling indices: the total fouling index (TFI), the hydraulic-irreversible fouling index (HIFI) and the chemical irreversible fouling index (CIFI) [12]. In 2014, Zupancic et al. proposed, for the first time, to use these fouling indices as a robust control system to manage the cleaning intervals in real time operation [13].

In this scenario, recent efforts have focused on incorporating palliative measures to reduce fouling on UF membranes. Yu et al. diminished the fouling rates associated to biological activities by 4.5 times by dosing potassium ferrate prior to the UF stage [14]. Also, Qu et al. tackled cell-related fouling by introducing manganese dioxide particles in a pre-treatment stage [15]. Other approaches to weaken fouling effects include the surface modification of the membranes. Juang et al. used a plasma treatment with 
methane/argon gas mixtures to alter the physicochemical properties of PVDF membranes. The tests conducted showed improvements as the solute adsorption and cake layer formation diminished [16]. Finally, a less invasive measure is to optimize the cleaning procedures conducted periodically on UF membranes. Lee et al. improved the efficiency of the chemical clean-in-place (CIP) from $33 \%$ to $82 \%$ by modifying chemical concentrations and operating conditions [17].

In order to appropriately select which palliative measures apply in every situation and how to optimize them, it is essential to determine how the membrane is affected depending upon the nature of fouling. Previous studies assess the impact of inorganic and organic compounds in fouling [18] as well as the role of microbial activity [19].

Because of all this, tracking the composition of the water feeding the UF stage from a quality stand point is also required for the optimization of the operation conditions. Bulk parameters such as total organic carbon (TOC), dissolved organic carbon (DOC) or UVabsorbance at $254 \mathrm{~nm}$ are commonly used in industry to monitor DOM along the process. These analytical techniques are easy to use, fast and economically affordable [20-21]. However, they do not provide information about the composition of DOM. In order to get further insight, more sophisticated analytical approaches are necessary, such as chromatographic separation techniques. One of these techniques is the high performance size exclusion chromatography (HP-SEC) coupled to oxygen carbon detection (OCD) and nitrogen carbon detection (NCD). DOM is fractionated, in the size exclusion column, by molecular size distribution [22-23]. The discretized fractions are associated to biopolymers, humic substances, building blocks, low molecular weight (LMW) neutrals and LMW acids [24]. The main drawback of this technique is the difficulty to be implemented for online monitoring and control of membrane 
performance and/or operation parameters, such as fouling detection, cleaning protocols or coagulant dosing needs.

In this line of research, fluorescence spectroscopy is seen as a suitable tool to continuously track the dynamics of DOM within water treatment processes [25-26]. It has the potential to be implemented online and it clusters DOM families based on their fluorescence properties [27]. Chemometric techniques, such as parallel factor analysis (PARAFAC), provide management and interpretation tools to extract the valuable information from the fluorescence excitation-emission (FEEM) spectra [28-29]. Li et al. used a $U_{280}$ light-emitting diode (LED) to excite both protein-like and humic-like compounds from 16 different water sources and suggested using online fluorescence to monitor DOM and predict disinfection by-products formation [30]. The suitability of using fluorescence spectroscopy to anticipate fouling in UF membranes was first demonstrated by Peiris et. al. [31]. In their publications, they combined fluorescence spectroscopy with principal component analysis (PCA) to correlate raw water quality with fouling of membranes [32-34]. Shao et al. [35] also evaluated the impact of DOM fractions on membrane fouling by correlating FEEM-PARAFAC data with the fouling indices developed by Nguyen et al. [12]. Their experiments, conducted with river water samples that exhibited a high variability in composition, showed that the protein-like fluorescence fraction correlated well with the applied fouling indices [35].

The effort of this study was directed to evaluate whether fluorescence spectroscopy coupled with PARAFAC is a suitable tool to monitor DOM in an UF train treating water of different quality (depending on whether the DWTP is fed with surface water, groundwater or blends of them), and to evaluate the suitability of using fluorescence 
measurements to anticipate/monitor fouling in advanced stages of the water treatment. The main objectives were: (i) to characterize and assess the dominant organic fractions within the UF streams, (ii) to test which organic fraction has a higher potential to foul the UF membranes by correlating quality with membrane performance and (iii) to evaluate the advantages and disadvantages of using FEEM-PARAFAC in the UF stage. The study was performed in two parallel stages. On one hand, UF was studied at a full-scale DWTP under actual operating conditions and, secondly, at a bench-scale device under controlled conditions (first with synthetic solutions and then with water from the DWTP).

\section{2.- Materials and Methods}

\subsection{Site description}

The DWTP is located in Sant Joan Despí, near Barcelona (Spain), and has a nominal capacity of $5.5 \mathrm{~m}^{3} / \mathrm{s}$ of produced water. The DWTP uptakes water from the lowest part of the Llobregat River, which is subjected to high oscillations in water quality in part due to changes in river flow $\left(3-20 \mathrm{~m}^{3} / \mathrm{s}\right)$, rainfall events and wastewater discharges from treatment plants upstream the river. Also, the DWTP draws water from wells when it is necessary (for example when the Llobregat water quality is too poor to be treated or when there is an excess in turbidity due to rainfalls). Figure 1 describes the overall process, which includes an initial pre-treatment with $\mathrm{ClO}_{2}(\mathrm{~g})$, coagulation, sedimentation and finally a sand filtration stage. It is at this point where, if required, groundwater is fed into the DWTP. The water train is split then in two parallel treatments: (i) a conventional line consisting in an ozonation process and granular 
activated carbon (GAC) filtration, and (ii) a membrane based treatment with UF, RO and, finally, a mineralization step. Both streams of produced water are blended, chlorinated and stored prior to distribution.

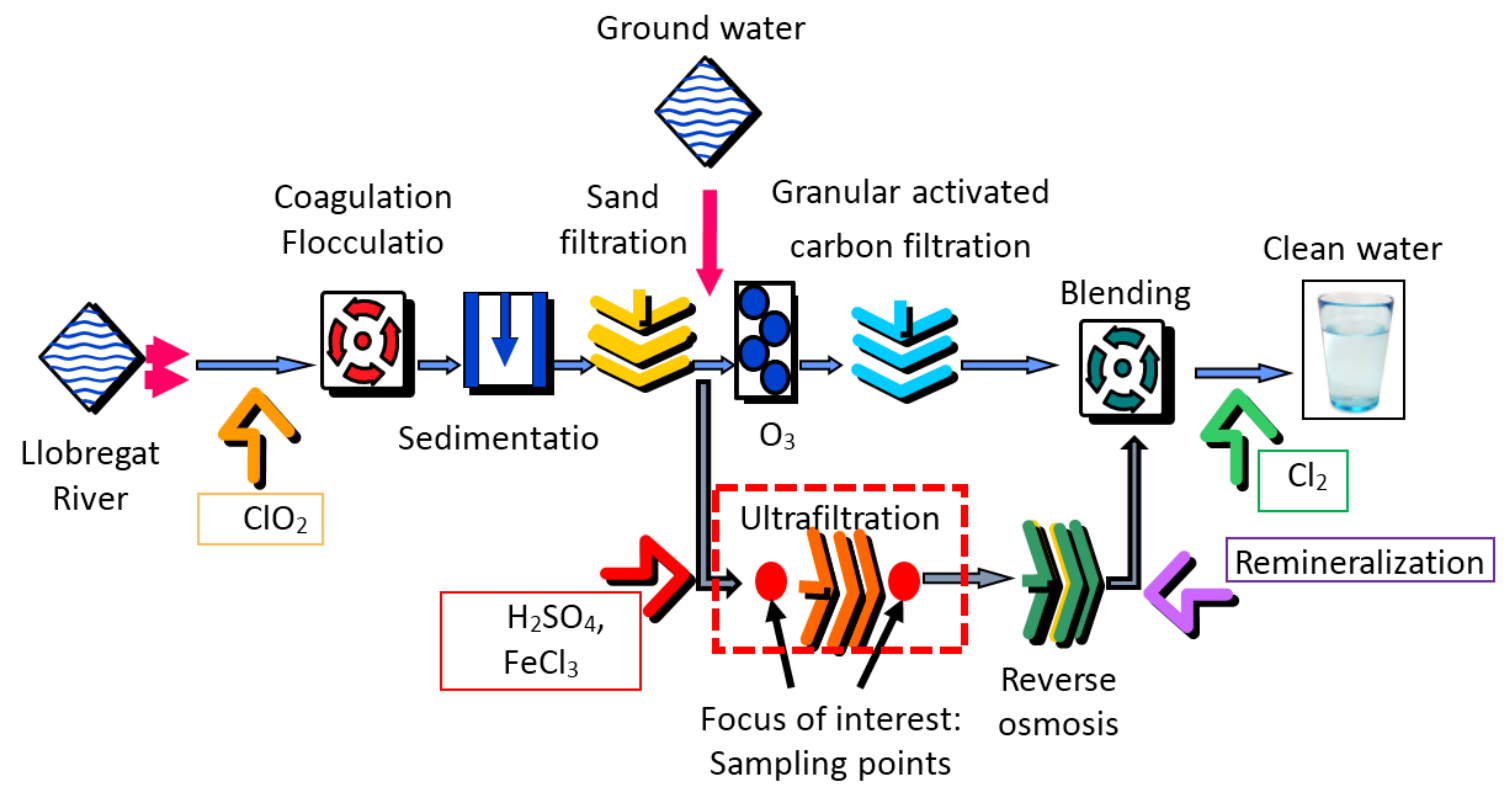

Figure 1.- Schematic description of the drinking water treatment plant located in Sant Joan Despí. The UF stage is circled and the sampling points are marked

Table 1 shows typical averaged values from both sand filtered and groundwater sources feeding the UF stream in plant.

Table 1.- Averaged data values and standard deviations measured at the Sant Joan Despí DWTP during 2015

\begin{tabular}{lcccc}
\hline & $\begin{array}{l}\text { Turbidity } \\
\text { (NTU) }\end{array}$ & Temperature $\left({ }^{\circ} \mathrm{C}\right)$ & $\begin{array}{l}\text { Conductivity } \\
(\mu \mathrm{S} / \mathrm{cm})\end{array}$ & $\begin{array}{l}\mathrm{UV}_{\mathbf{2 5 4}} \\
(\mathrm{Abs} / \mathbf{1 0 0} \mathbf{c m})\end{array}$ \\
\hline $\begin{array}{l}\text { Sand filtered } \\
\text { water (SFW) }\end{array}$ & $0.27 \pm 0.15$ & $17.7 \pm 7.2$ & $1386 \pm 103$ & $6.78 \pm 0.15$ \\
\hline Groundwater & $<0.1$ & $18.5 \pm 1.5$ & $1677 \pm 22$ & $1.53 \pm 0.13$ \\
\hline
\end{tabular}




\subsection{Sampling procedures}

A total of 95 samples were collected using $100 \mathrm{~mL}$ glass bottles during 2015 . They were stored at $4{ }^{\circ} \mathrm{C}$ and analyzed within a maximum of three days after acquisition. Stability of DOM in samples was studied prior to the campaigns and FEEM spectral changes detected within these three days were found to be below $3 \%$.

\section{3.- Bench-scale membrane ultrafiltration setup}

A bench-scale UF setup was used in order to have a better control of the membrane performance and the feed water composition during each experimental run. The system was designed to mimic the operating conditions as in full-scale plant. Figure 2 shows the scheme of the bench-scale UF setup. A PVDF membrane contained in a $15 \mathrm{~L}$ tank was used to filter water during filtration cycles of 60 minutes at constant flow. The tank was provided with a manometer to monitor transmembrane pressure (TMP) during the experiment. A second tank was used to supply water and keep the level of the filtration tank as well. Permeate was pumped by means of a Heidolph pump (drive 5201) and collected on a vessel and weighted on an electronic balance. During the experiments, data obtained from the manometer and the mass balance was sent to the computer via a data logger and recorded. An in-house made user interface program (using MATLAB 2013b) was used to manage the filtration cycles. Also, Table 2 describes the membrane specifications and the operating conditions of the experiments. 


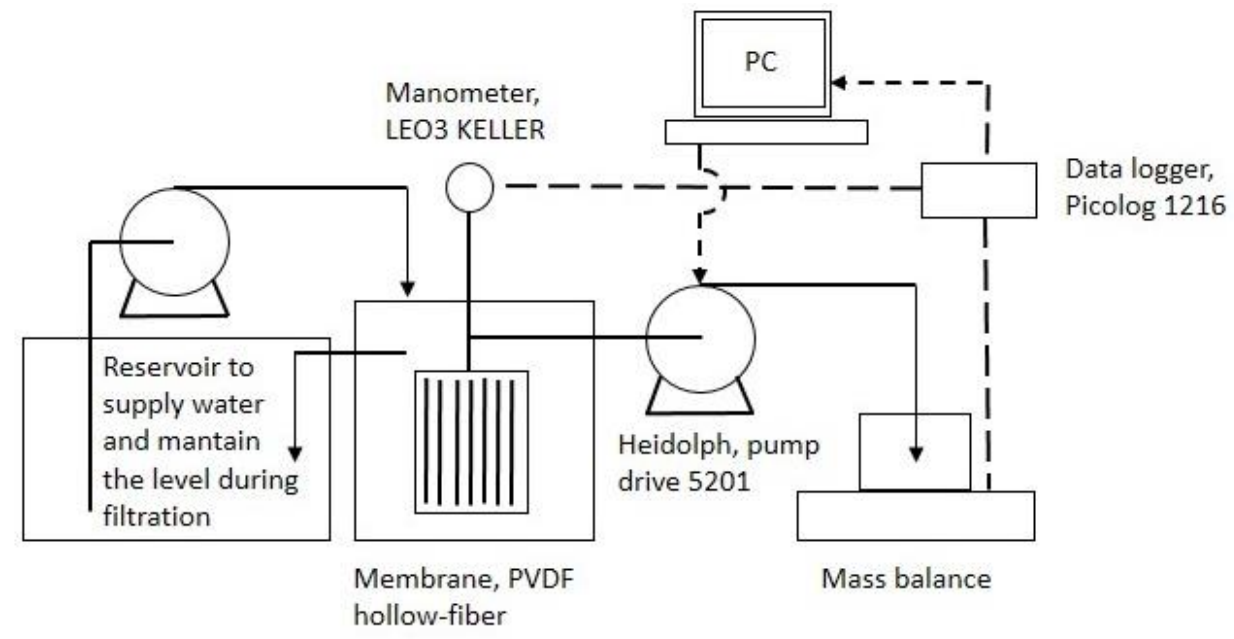

Figure 2.- Scheme of the bench-scale ultrafiltration dead-end set-up

Table 2.- Membrane specifications and operating conditions

\begin{tabular}{cc}
\hline UF Membrane specifications and operating conditions \\
\hline Material & PVDF \\
Type & Hollow fiber \\
Configuration & Dead end / Outside-inside \\
Area & $0.042 \mathrm{~m}^{2}$ \\
Pore diameter & $20 \mathrm{~nm}$ \\
Flux & Constant, $40{\mathrm{~L} \cdot \mathrm{m}^{-2} \cdot \mathrm{h}^{-1}}^{\text {Permeability }}$ \\
Temperature & $350-150 \mathrm{~L} \cdot \mathrm{m}^{-2} \cdot \mathrm{h}^{-1} \cdot \mathrm{bar}^{-1}$ \\
Backwash frequency & $10{ }^{\circ} \mathrm{C}$ \\
Backwash duration & $60 \mathrm{minutes}$ \\
Number of cycles in every run & $2 \mathrm{minutes}$ \\
Parameters used to quantify fouling & 10 \\
\hline
\end{tabular}

2.4.- Procedures performed to characterize, monitor and quantify the impact of DOM in the UF stage

The work presented here was divided in three different tasks. First, there was a characterization stage in which water feeding the full-scale UF stage was analyzed; 
groundwater and sand filtered water were evaluated separately and blends from both water sources were also studied.

Second, synthetic solutions were prepared with the objective to gain insight about the suitability of using different analytical tools to track DOM and also, to quantify the impact of these synthetic waters in membrane performance. Humic acid (HA, SigmaAldrich) and bovine serum albumin (BSA, Sigma-Aldrich) were selected as model foulants as their fluorescence spectra resemble those organic fractions found in water. Fluorescence measurements as well as more conventional analytical techniques (TOC and $U_{254}$ ) were used to compare and quantify the contributions of $\mathrm{HA}$ and BSA to fouling. A total of four solutions of HA and three solutions of BSA ranging from 1 to $4 \mathrm{mg}$ $C \cdot \mathrm{L}^{-1}$ were used. The solutions were prepared by dosing the synthetic foulants in beakers filled with ultrapure water, agitated for 15 minutes to ensure homogeneity and finally filtered using $0.45 \mu \mathrm{m}$ PVDF membranes.

Third, bench-scale filtrations tests were also carried out with water from the UF inlet of the full-scale DWTP. A total of thirteen different runs were performed. For each run, the inlet water was analyzed through fluorescence spectroscopy and absorbance spectroscopy at $254 \mathrm{~nm}\left(\mathrm{UV}_{254}\right)$.

\section{5.- Calculation of the fouling indices}

The total fouling index (TFI) and the hydraulically irreversible fouling index (HIFI) were calculated to quantify fouling in the bench-scale UF membranes. These fouling indices were first developed by Nguyen et al. based on a resistances-in-series model [12]. The flux through a membrane (J, flow per unit area) can be described as: 


$$
J=\frac{T M P}{\mu R}
$$

Where TMP is the transmembrane pressure, $R$ is the resistance the liquid must overcome to permeate and $\mu$ is the viscosity of the liquid. $\mathrm{R}$ can break down into smaller contributions: the intrinsic resistance of the membrane when there is no fouling and the resistance accounting for fouling of the membrane. The model assumes that the resistances due to fouling increase linearly with the volume of permeate produced. Also, the specific flux at any specific volume (Vs, volume filtered per unit area) can be expressed as:

$$
\left(U_{s}\right)_{V s}=\left(\frac{J}{T M P}\right)_{V s}
$$

Js can be normalized by the expression at $\mathrm{Vs}=0$, where the membrane is still clean, as follows:

$$
\frac{\left(J_{s}\right)_{V S}}{\left(J_{s}\right)_{0}}=\frac{\left(\frac{J}{T M P}\right)_{V s}}{\left(\frac{J}{T M P}\right)_{0}}=\frac{R_{0}}{R_{v s}}=\frac{1}{1+\frac{R_{f}}{R_{0}} V_{S}}
$$

Where $R_{0}$ is the resistance of the membrane at $V_{s}=0$ and $R_{f}$ accounts for the resistance associated to fouling. The expression can be rearranged as:

$$
\frac{1}{J s^{\prime}}=1+\frac{R_{f}}{R_{0}} V_{s}=1+(F I) V_{s}
$$

Where $\mathrm{Fl}$ is the fouling index expressed as unit area per volume and Js' accounts for the specific flux normalized. Depending upon the filtration intervals in which equation 6 is used, different contributions to fouling are obtained. For instance, if calculated between 
two hydraulic cleanings, the TFI is calculated. The HIFI can be determined by measuring fouling in an interval comprised between chemical cleaning cycles and it accounts for fouling not recovered with hydraulic cycles.

\subsection{Analytical techniques used for organic matter characterization}

EEM fluorescence analysis were performed in a $1 \mathrm{~cm}$ cuvette using a fluorescence spectrometer (AMINCO-BOWMAN Series 2) by scanning 251 individual emission wavelengths $(250-500 \mathrm{~nm}$ ) with $5 \mathrm{~nm}$ increments of excitation wavelengths between 200 and $400 \mathrm{~nm}$. However, since the lower region was noisy, the excitation wavelengths used ranged from 245 to $400 \mathrm{~nm}$. For each sample analyzed, a FEEM was generated with an intensity value in each coordinate point. The scan rate was set to $18 \mathrm{~nm} \cdot \mathrm{s}^{-1}$ for all samples analyzed, the slit widths were both adjusted to $5 \mathrm{~nm}$ and the photomultiplier tube voltage was set to $750 \mathrm{~V}$. Prior to the analysis the samples were tempered at room temperature. The spectra were acquired in the ratio mode to ensure normalization of the signal and enable comparison within samples analyzed.

TOC concentration in water samples was determined by means of a total carbon analyzer at $680^{\circ} \mathrm{C}$ (TOC Shimadzu Model V CSH). The detection limit of the system was $1 \mathrm{mg} \mathrm{C} \cdot \mathrm{L}^{-1}$.

Absorbance spectroscopy at a wavelength of $254 \mathrm{~nm}$ was conducted on a DR5000 spectrophotometer (Hach Lange) equipped with $1 \mathrm{~cm}$ cuvettes.

The Liquid chromatography coupled with oxygen carbon detection (LC-OCD) analysis was performed by DOC-laboratories, Germany (DOC-Labor, Karlsruhe). The samples were sent under refrigeration and analyzed within three days from acquisition. The 
technique separates DOC in water by size exclusion chromatography followed by a multidetection system for organic carbon, organic bound nitrogen (OND) and UVabsorbance into non-chromatographic and chromatographic fractions. The latter is further discretized into biopolymers (BP), humic substances (HS), building blocks (BB), low molecular weight (LMWN) neutrals and LMW acids (LMWA). The detection limit of the system for each fraction is $0.01 \mathrm{mg} \cdot \mathrm{L}^{-1}$. Fuller accounts on the LC-OCD fundamentals and analysis are detailed in Huber et al. [24].

\section{7.- Fluorescence data treatment}

The resulting matrices containing $251 \times 32$ emission intensity readings for each water sample were further analyzed with PARAFAC to decompose them into a set of trilinear terms and a residual array. This was done in order to estimate the number of organic fractions present in our samples. In order to conduct the modeling, the N-way v.3.00 Toolbox for MATLAB was used [36]. The first and second order Rayleigh diagonals were trimmed and the samples were smoothed. The morphology of the contour plots obtained from the model, the explained variation, the split half validation and also the residual arrays were the parameters used to select the appropriate number of components in the model. The maximum fluorescence intensity $\left(F_{\max }\right)$ was used to track changes in DOM. The $F_{\max }$ is determined by selecting the point of maximum intensity for each factor in each sample. The PARAFAC model can be written as:

$$
X_{i j k}=\sum_{f=1}^{F} a_{i f} b_{j f} c_{k f}+E_{i j k}
$$


Where $X_{i j k}$ is the matrix used providing intensity values at specific coordinate points, $a_{i f}$, $b_{\mathrm{jf}}, c_{\mathrm{kf}}$ correspond to the scores, the estimated emission spectrum and the estimated excitation spectrum at specific coordinates, respectively. Also, the F value defines the number of components in the model and the $E_{i j k}$ accounts for the residual variation not explained in the model [37]. The model was corroborated using the split half validation in which the sample spectra were fractionated and modeled separately and finally compared for validation.

\section{3.- Results and discussion}

\section{1.- DOM characterization of ground and surface water blends with FEEM-PARAFAC}

In this study, a total of 95 samples of UF feed and permeate were collected during 2015 and used to obtain a global PARAFAC model in the UF stage. During this year the DWTP was fed surface water (SFW) from the Llobregat River, groundwater (GW) from its aquifer or blends of them (on average GW accounted for approximately $20-30 \%$ of the water fed to the plant). The PARAFAC model obtained contained seven different components. Component C1 (exhibiting a maximum at ex/em 280/329 nm) and component C2 (exhibiting two maxima at ex/em 245\&285/421 nm) derive from the same group of fluorophores [38]. Components C3-C7 exhibited a single maximum at ex/em 245/353 nm, 250/392 nm, 265/450 nm, 275/306 nm and 250/454 nm, respectively. Figure 3 shows the FEEM spectra of each component. Based on the classification proposed by Chen et al., components C1 and C3 are linked to microbial byproducts, components $\mathrm{C} 2, \mathrm{C} 4$ and $\mathrm{C} 7$ are related to fulvic acids, component $\mathrm{C} 5$ fall into 
the region associated to the humic acid and, finally, component $\mathrm{C} 6$ is linked to aromatic proteins II [39]. The Open Fluor data base was also used to match the components found in this study with studies conducted elsewhere. To do the matching for each component, the Tucker congruence coefficient is used. In this case, all components matched previous studies. It is noteworthy that component C7 was identified only once, suggesting that it could just well be a component arising from noise or the scattering not completely removed. Further information about the PARAFAC model is described in Table 3.
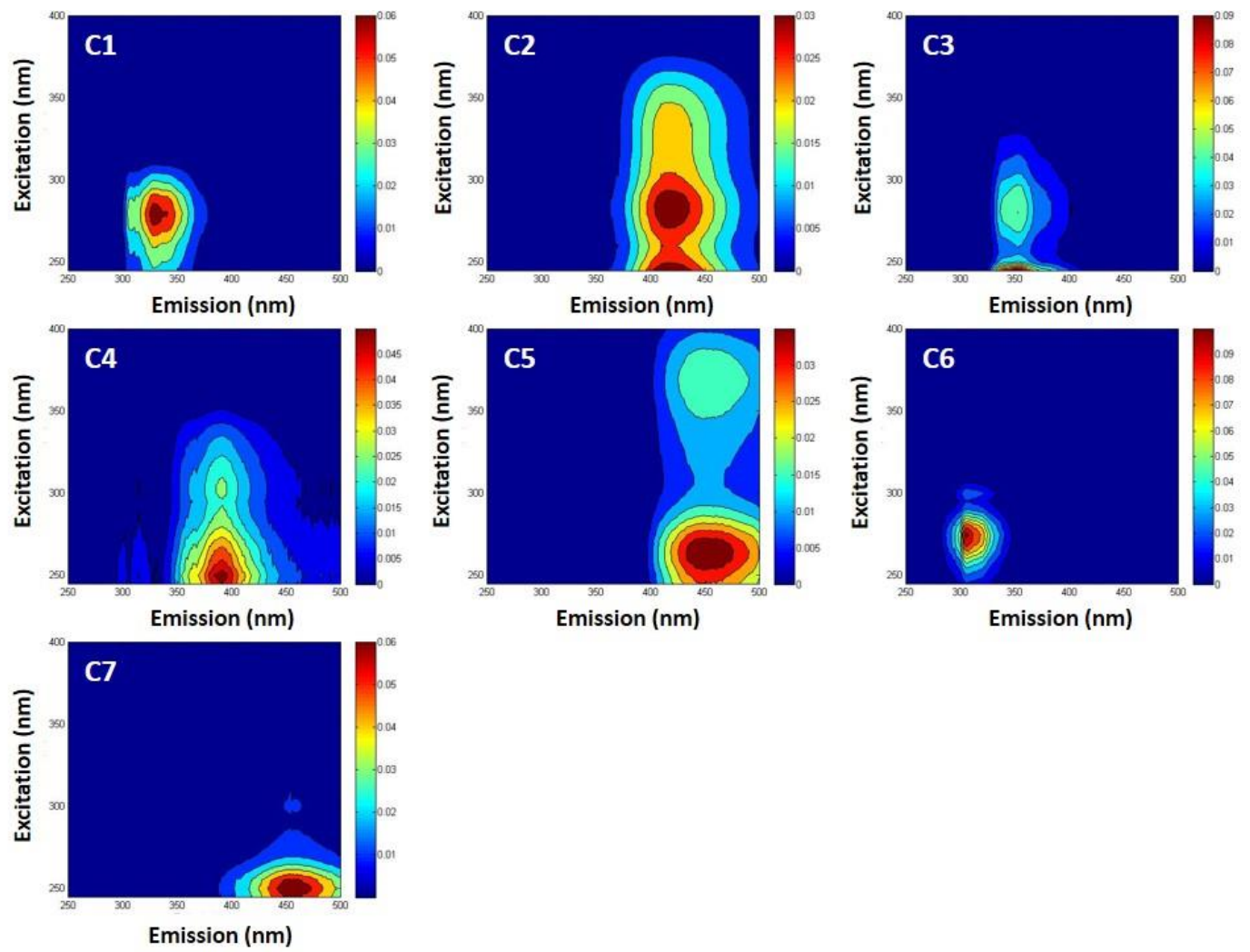

Figure 3.- FEEM contour plots of the seven components obtained by using FEEM-PARAFAC with samples from the UF stage 


\begin{tabular}{cc}
\hline № of components & 7 \\
№ of samples used & 95 \\
Outlier samples & 1 \\
Explained Variation (\%) & $>99.7 \%$ \\
Split half analysis & $92 \%$ similarity \\
\hline
\end{tabular}

FEEM of five GW samples and five SFW samples were averaged separately to visually inspect and compare the morphology of their fluorescence contour plots. Also, as these samples were included in the PARAFAC model, the residual FEEM from the samples were also averaged (for all 5 samples) and evaluated to see how well the model was fitted to each water source. Figure $4 a$ and $b$ exhibit the contour plots obtained for each water source. Comparing the fluorescence signal intensity within both water sources, SFW showed higher overall intensity $F_{\max }$ values. The ratios (SFW/GW) were calculated for all seven components; the greater differences were found for component C5 (ratio 4.18) and component $\mathrm{C} 6$ (ratio 3.52) associated to humic acids and microbial by-products. Also, component $\mathrm{C7}$ exhibited much higher $F_{\max }$ values for $\mathrm{GW}$ samples (ratio 0.14). Finally, the ratios obtained for components C1-C4 were 2.98, 2.57, 1.98, 1.42 and 4.15, respectively. Also, Figure $4 \mathrm{c}$ and $\mathrm{d}$ show the residual EEM data not described with PARAFAC. Besides noise, there is a region emitting localized fluorescence, identified in both water sources, which may be related to a fluorophore. According to the previous classification, the fluorescence signal is related to aromatic proteins I [39]. However of 
that, the global PARAFAC model described fairly well the samples from both water sources.
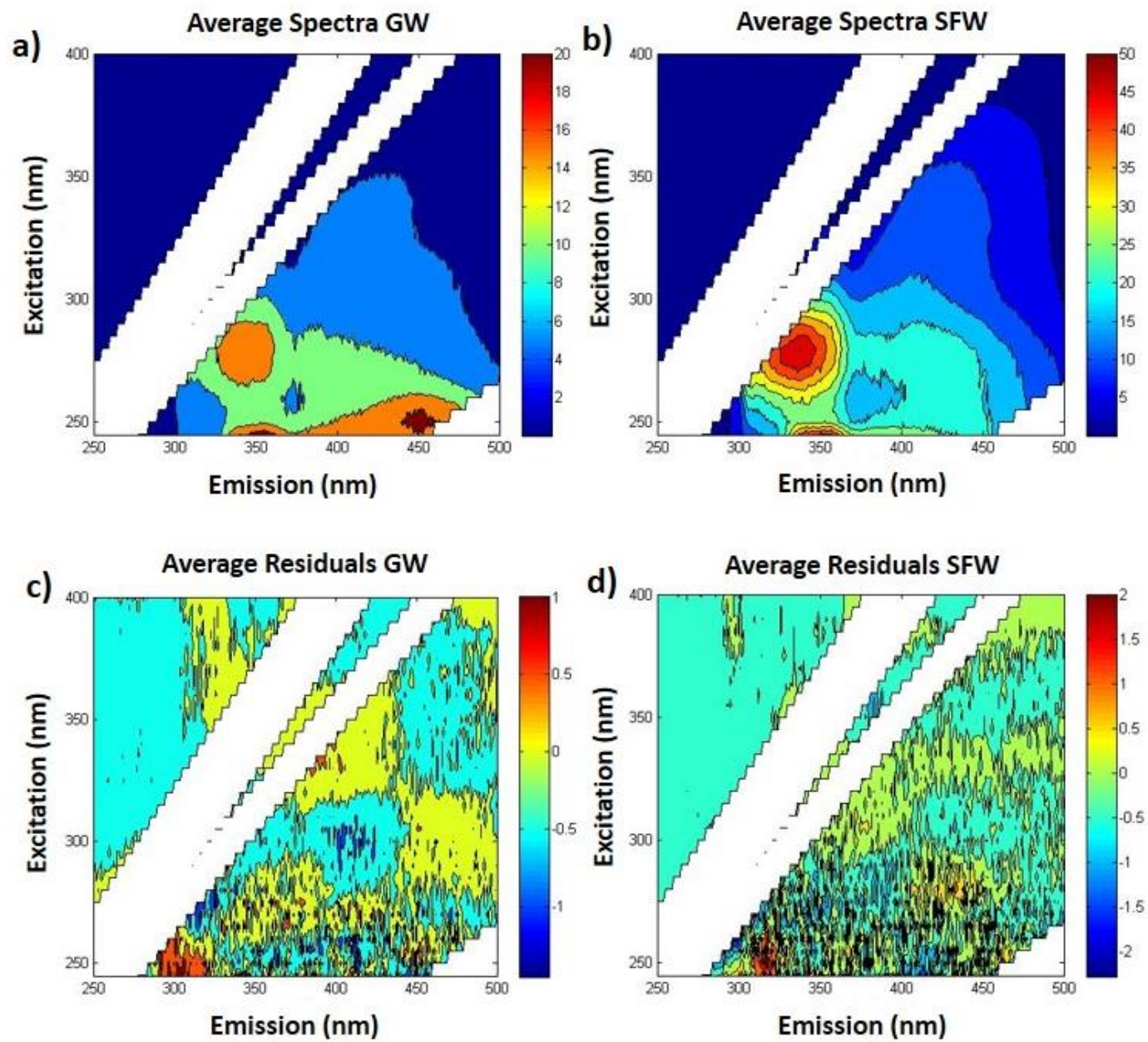

Figure 4.- Averaged EEM data from a) five GW samples and b) five SFW samples feeding the UF stage as well as the residual EEM obtained from conducting PARAFAC for $\mathrm{C}$ ) the GW samples and d) the SFW samples

DOM fluorescence signal in water samples was compared to that of synthetic humic acid (HA) and bovine serum albumin (BSA), which were used as they resemble to a certain extent those organic fractions found in water, and consequently, they fluoresce in similar regions within the fluorescence spectra [40][41]. These synthetic compounds were employed (i) to compare the information provided by FEEM-PARAFAC with respect to other bulk parameters such as $\mathrm{DOC}$ and $\mathrm{UV}_{254}$, and (ii) to postulate them as potential 
surrogates to quantify the identified regions in terms of model compounds. Figure $5 \mathrm{a}$ and $b$ show the contour plots of the HA and BSA, respectively. Figure $5 c$ and $d$ show the calibrations ( $F_{\max }$ vs DOC concentration) performed from different synthetic solutions of both model compounds ( $\mathrm{HA}$ and $\mathrm{BSA}$ ). The solutions were prepared with only 1 component at a time. Both the DOC determination and the $\mathrm{UV}_{254}$ analysis showed linearity with $F_{\max }$ values. However, the $\mathrm{UV}_{254}$ exhibited extremely low signal when the solution of BSA was analyzed as compared to the calibrations with solutions of HA. Figure 5 shows how fluorescence spectroscopy of model compounds has potential to be used in quantification of DOM as it can correlate DOC and UV values. However, it is a need to extend the number of model analytes to provide a wide description of DOM emitting fluorescence.

a)

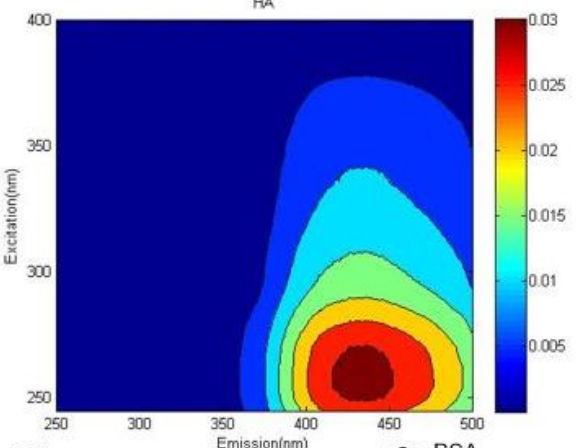

c)

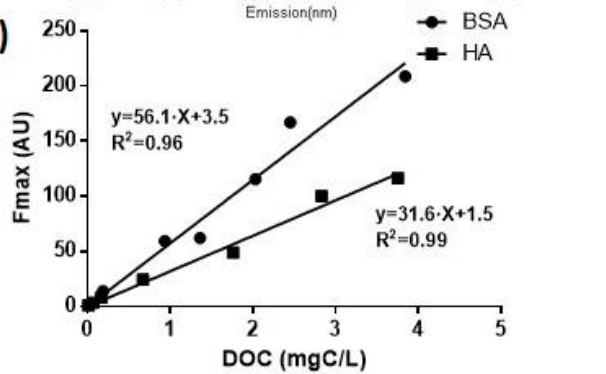

b)

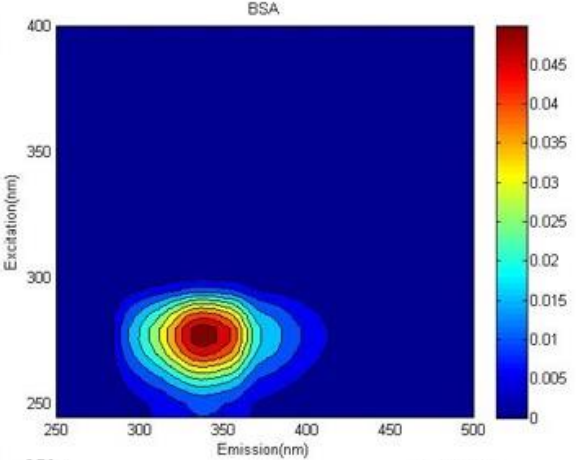

d)

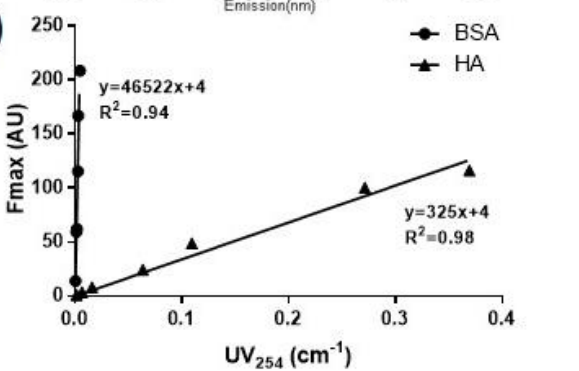

Figure 5.- EEM contour plots obtained by using FEEM-PARAFAC of the a) HA and b) BSA, correlation plots of c) $F_{\max }$ and DOC and d) $F_{\max }$ and UV254 


\section{2.- Monitoring DOM variability in the UF stage by using FEEM and LC-OCD}

The variability of DOM in water feeding the UF is affected by external factors such as river flow and seasoning but also by the contribution of both GW and SFW as both sources are blended together. Figure 6 shows the average $F_{\max }$ values for the seven different PARAFAC components measured with FEEM data from the UF feed during 9 months of operation. Overall, the $F_{\max }$ values exhibited high variability. Component $\mathrm{C} 7$ showed abnormally high variability with a relative standard deviation (RSD) exceeding $100 \%$ and may not be describing an organic compound as it behaves completely different from the other components. Also, components $\mathrm{C} 6$, associated to microbial byproducts, showed RSD values of $65 \%$. The other components showed RSD values ranging from $30-50 \%$.

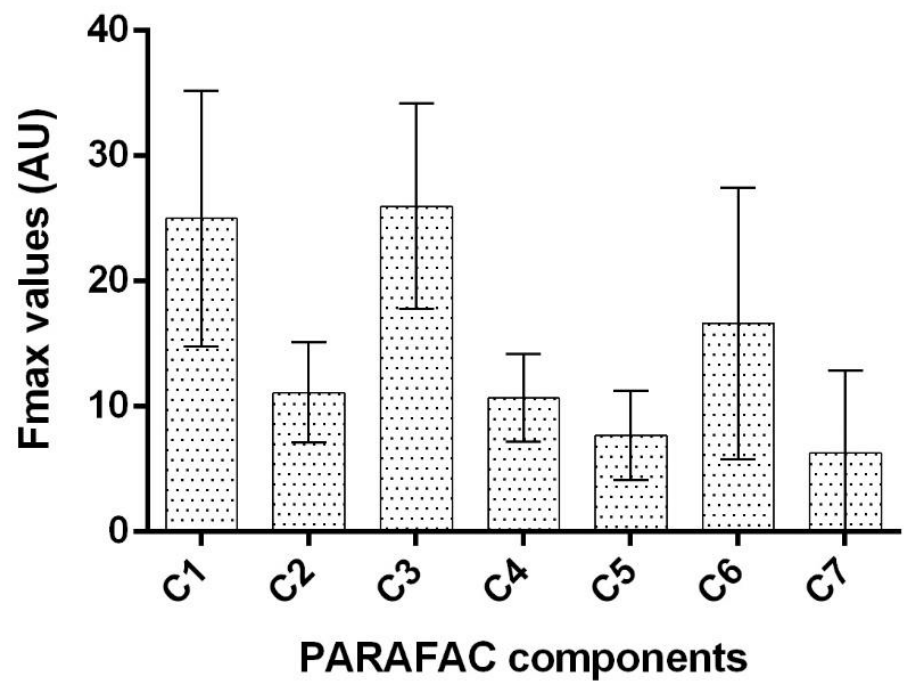

Figure 6 Variability of $F_{\max }$ values in the UF feed for each component calculated with PARAFAC

In addition to evaluating the DOM variability in the UF feed, a set of twenty pairs of samples from the feed and permeate streams were analyzed and Fmax values for each component were used as surrogates for rejection estimation. The percentages 
decreases of Fmax exhibited confidence levels overlapping zero, making evident that no significant removal was observed for any of the components.

The foulants accumulated on the membrane could not be calculated through a mass balance for a variety of reasons. First, total flow rates and volumes during the studied filtration period, which are required for the mass balance, were unknown. It must be stated here that the UF stage in the DWTP of study is composed of 9 different trains, which are operated on a rotating schedule (while some are on a filtration mode others are on a backwashing or cleaning mode), so that the plant can continuously operate. This complex operation regime posed difficulties in calculating volumes and applying mass balances reliably. A second reason more determinant is that, with regard to FEEM analysis, fluorescence intensity signal cannot be converted into concentrations (also required for applying a mass balance). The reason is that the value of the fluorescence intensity depends on the concentration of the fluorophore, but also on the molar absorptivity and the quantum yield, which are unknown. As outlined by the manuscript, further research is needed to convert intensity values to concentration values. Consequently, monitoring DOM fraction removal by FEEM-PARAFAC is at this stage more qualitative than quantitative and then efforts to convert component $F_{\max }$ intensity values into mass removal needs yet to be developed.

Moreover, DOM removal ratios on the UF stage were measured by monitoring changes of samples from the UF feed, permeate and backwash by using LC-OCD-OND. Comparison between the UF feed and permeate analysis showed that the UF system removed mainly biopolymers (48\%) while building blocks (-2\%), humic substances $(-5 \%)$ and low-MW fractions (1\%) were not rejected. Additionally, the histograms between 
feed water, UF permeate and UF backwash were calculated (Figure 7). The results show that the solution removed during a backwash episode (hydraulic cleaning performed cyclically in which a backward flow is pumped through the membrane) exhibit a high content in BP fraction. Even though the BP fraction was found to be rejected the most, reaching almost $50 \%$ values, such fraction was not captured when using FEEM-PARAFAC. The global variation in DOC concentration between the UF feed and permeate was $6 \%$ (3929 $\mu \mathrm{gC} \cdot \mathrm{L}^{-1}$ feed vs $3696 \mu \mathrm{gC} \cdot \mathrm{L}^{-1}$ permeate). Ao et al. 2016, found little rejections in protein-like fractions when using fluorescence spectroscopy (whereas the overall DOM rejection was close to $10 \%)$. In their analysis of the fouled membranes by using Fourier transform infrared spectroscopy (FTIR), they identified polysaccharides as the main membrane foulants [42]. Their results are in agreement with the analysis performed in this study regarding LC-OCD and fluorescence spectroscopy.

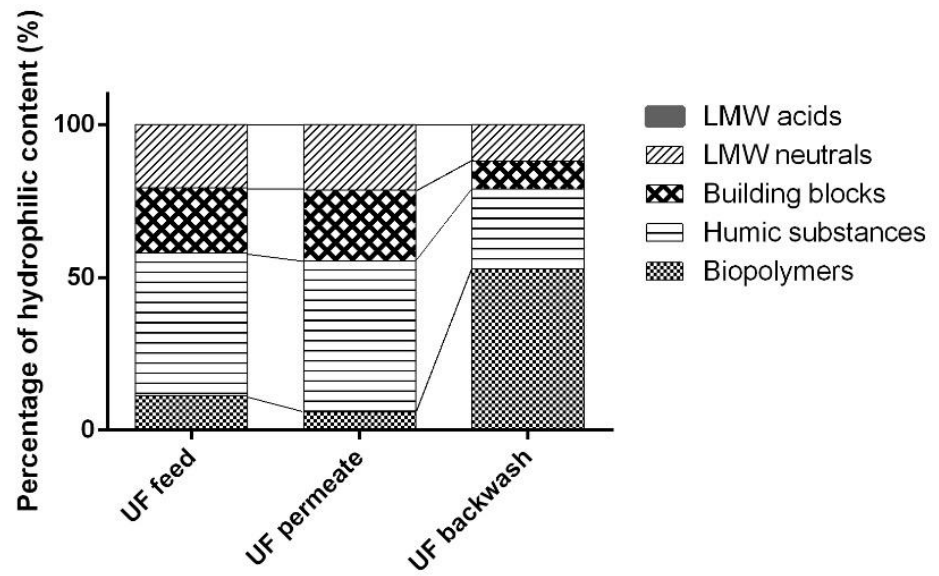

Figure 7.- Percentage variation of the organic content between the different streams obtained from LC-OCD analysis

\subsection{Monitoring UF membrane fouling by using FEEM-PARAFAC}

Water feeding the full-scale UF stage consisting of treated SFW and GW blends was collected to test its potential to foul the UF membrane in the bench-scale system. First, 
water was characterized through fluorescence spectroscopy and $U_{254}$. Secondly, the water was filtered using the experimental setup described in section 2 and both the TFI and HIFI values were calculated. A total of thirteen experimental runs were conducted each lasting 10 hours so that the HIFI values could be considered to be representative of the habitual fouling on the UF membrane. Figure 8 exhibits the plots obtained from correlating water quality parameters with operating performance. Figure $8 a$ and $b$ show the correlations between the FEEM-PARAFAC components located in the region associated to microbial byproducts (C1 and $\mathrm{C} 6$ ). It is observed that, even though both components fall in the same region from the fluorescence spectra, they behave differently. Component $\mathrm{C} 1$ shows correlation with both the TFI and HIFI whereas no correlation exists regarding component C6. Figure $8 c$ and $d$ show the correlations for the FEEM-PARAFAC components associated to the fulvic acids. In this case, both components $\mathrm{C} 2$ and $\mathrm{C} 4$ correlate with TFI and HIFI with greater correlations observed for component C2. On the other hand, poor correlations are found for component C3, linked to the protein-like fraction (see Figure $8 \mathrm{e}$ and f). Also, component $\mathrm{C} 5$ is located in the region of humic acids and shows the highest correlations among all the parameters evaluated (see Figure $8 \mathrm{~g}$ and h). Finally, the measurements with absorbance at $254 \mathrm{~nm}$ show similar correlations to those for the humic-like compounds. 

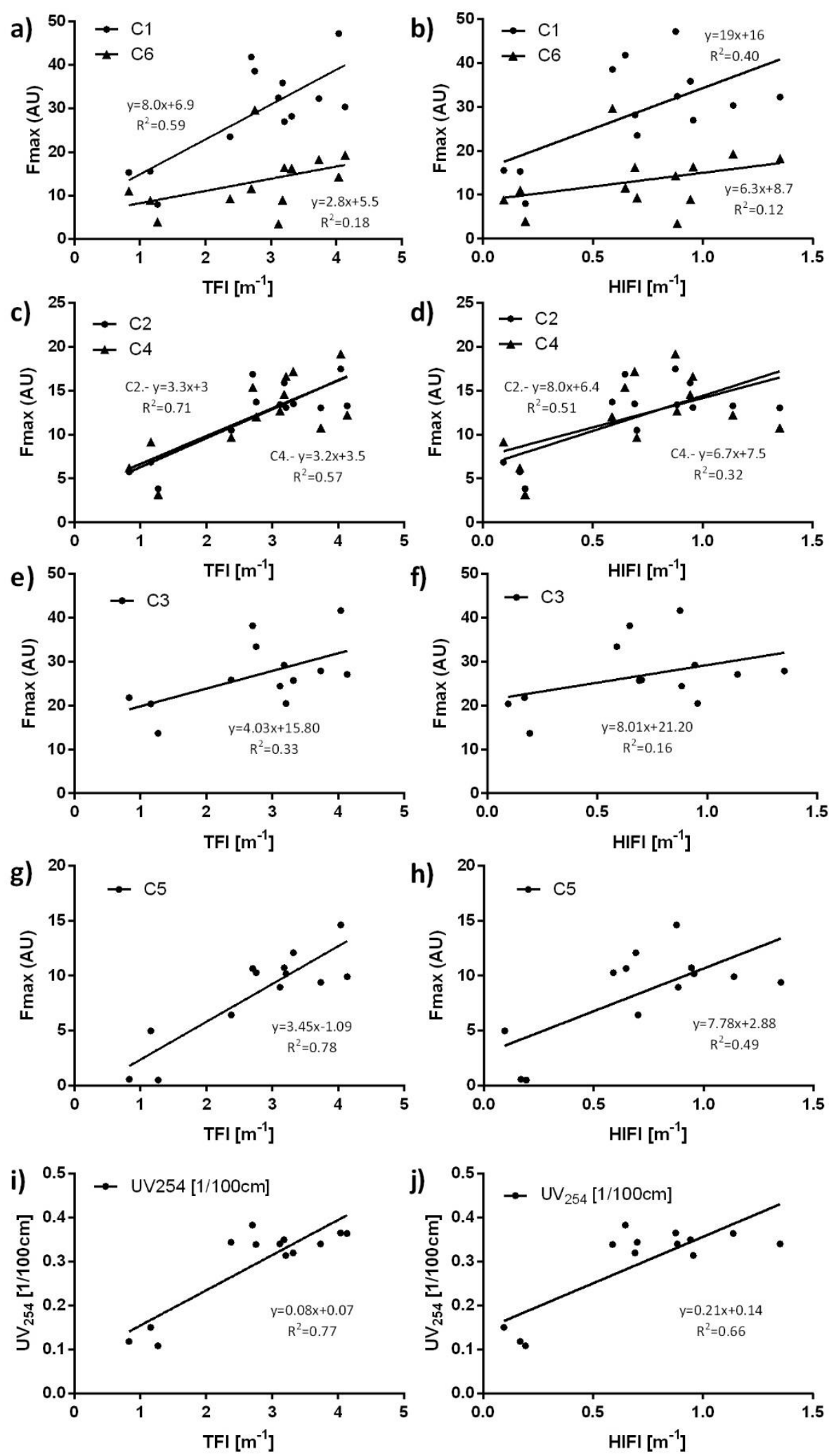

Figure 8.- Correlation plots obtained from the bench-scale UF runs performed: a) TFI vs C1 and C6 b) HIFI vs C1 and C6 c) TFI vs C2 and C4 d) HIFI vs C2 and C4 e) TFI vs C3 f) HIFI vs C3 g) TFI vs C5 h) HIFI vs C5 i) TFI vs UV 254 j) HIFI vs $U V_{254}$ 
Synthetic HA and BSA were also used to quantify its isolated effect on fouling of the UF membranes (Figure 9a and b). For both model foulants, TFI increased as the concentration of the compounds was higher. Based on the calibrations previously performed (Figure 5), at similar DOC values the contribution of BSA to fouling was higher than the contribution of HA. Moving to the UF inlet streams, however, the results cannot be likened so easily because, as it was mentioned earlier, the amount of protein signal obtained for SFW and GW could be a combination of HMW and LMW compounds, as opposed to the case of using BSA where it is predominantly HMW compounds.

a)

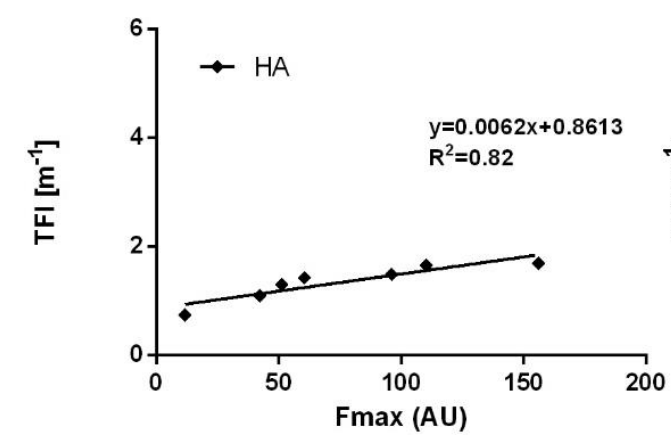

b)

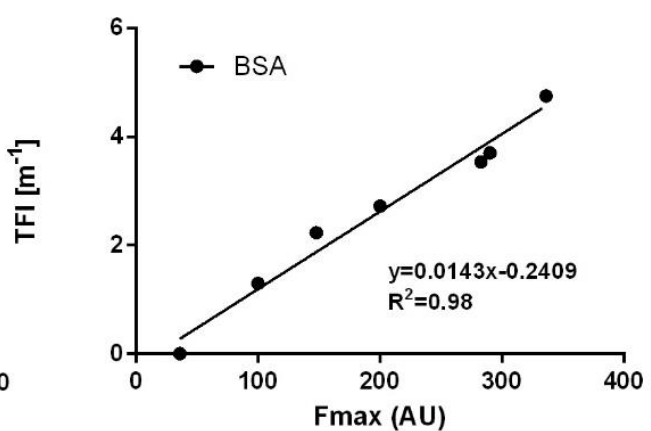

Figure 9.- Correlations between $F_{\max }$ and TFI values obtained from conducting bench-scale experiments using solutions of e) synthetic HA and b) synthetic BSA

Then, according to the results in this study, the protein fraction obtained from FEEMPARAFAC did not capture the contribution of BP to fouling even though the LC-OCD-OND analysis performed proved accumulation of BP in the membranes. Thus, either BP accumulating on the membranes did not have a significant impact on the global fouling or monitoring BP fouling with fluorescence may not be plausible in this scenario. Two different situations would explain this last hypothesis: (i) when there is a high content of LMW compounds in water (e.g. in advanced steps of the water treatment processes) 
and (ii) when the water contains a high content of non-fluorescent organic fraction (i.e. Polysaccharides).

Future research will include the use of fluorescence spectroscopy coupled with other techniques to account for the non-fluorescence fraction of NOM as well as to account for particulate/colloidal matter and inorganic compounds affecting membrane performance. Also, the fluorescence sensor will be integrated online to monitor NOM in water treatment plants and the analysis will be extended to other DWTP stages. Finally, the authors will also focus on improving quantification protocols to convert intensity values to concentration values.

\section{4.- Conclusions}

In this study, samples from a full-scale UF stage, originating from sand filtered and groundwater blends, were analyzed and successfully modelled via FEEM-PARAFAC. A model containing seven different components best fitted the experimental data and was used to characterize the organic fractions within the water samples. The $F_{\max }$ values for each component in each sample showed high variability in relation to water feeding the full-scale UF plant.

The fluorescence spectra from the model foulants tested emitted in similar regions as those spectra from complex waters in plant. The analysis showed good correlations between the $F_{\max }$ values and bulk parameters such as DOC and absorbance at $254 \mathrm{~nm}$. Unlike with the absorbance at $254 \mathrm{~nm}$, the reduction in fluorescence signal intensity for BSA was less significative.. The bench scale experiments performed showed that both 
$\mathrm{HA}$ and BSA contributed to foul the membranes as the $F_{\max }$ values correlated well with the fouling indices calculated.

Additionally to the experiments conducted with synthetic waters, the membrane performance was also assessed when filtering complex waters from plant. The correlation plots between the PARAFAC components and the fouling indices pointed at a component linked to microbial byproducts $(\mathrm{C} 1)$ and humic-like components $(\mathrm{C} 2, \mathrm{C} 4$ and $\mathrm{C5}$ ) as the ones showing higher correlations. Even though the LC-OCD-OND analysis identified biopolymers as the fractions most rejected by the UF membranes, this information was not captured via FEEM-PARAFAC.

\section{5.- Acknowledgements}

This work was conducted under the financial support of the Agència de Gestió d'Ajuts Universitaris i de Recerca (AGAUR) and Aigües de Barcelona (AB) through the Industrial PhD Program supporting M. Vera (2013-DI-026). Authors would like to thank the personal at the Sant Joan Despí DWTP for their cooperation throughout the study.

\section{6.- References}

[1] T. Miyoshi, M. Hayashi, K. Shimamura, and H. Matsuyama, "Important fractions of organic matter causing fouling of seawater reverse osmosis ( SWRO ) membranes," Desalination, vol. 390, pp. 72-80, 2016.

[2] R. Epsztein, O. Nir, O. Lahav, and M. Green, "Selective nitrate removal from groundwater using a hybrid nanofiltration-reverse osmosis filtration scheme," Chem. Eng. J., vol. 279, pp. 372-378, 2015. 
[3] M.-L. Pype, M. G. Lawrence, J. Keller, and W. Gernjak, "Reverse osmosis integrity monitoring in water reuse: The challenge to verify virus removal - A review," Water Res., vol. 98, pp. 384-395, 2016.

[4] R. F. Bangash, A. Passuello, M. Sanchez-Canales, M. Terrado, A. López, F. J. Elorza, G. Ziv, V. Acuña, and M. Schuhmacher, "Ecosystem services in Mediterranean river basin: Climate change impact on water provisioning and erosion control," Sci. Total Environ., vol. 458-460, pp. 246-255, 2013.

[5] A. Momblanch, J. Paredes-Arquiola, A. Munné, A. Manzano, J. Arnau, and J. Andreu, "Managing water quality under drought conditions in the Llobregat River Basin," Sci. Total Environ., vol. 503-504, pp. 300-318, 2015.

[6] K. M. Sassi and I. M. Mujtaba, "Optimal design and operation of reverse osmosis desalination process with membrane fouling," Chem. Eng. J., vol. 171, no. 2, pp. 582593, 2011.

[7] F. Gao, J. Wang, H. Zhang, Y. Zhang, and M. A. Hang, "Effects of sodium hypochlorite on structural/surface characteristics, filtration performance and fouling behaviors of PVDF membranes," J. Memb. Sci., vol. 519, pp. 22-31, 2016.

[8] D. Wei, Y. Tao, Z. Zhang, and X. Zhang, "Effect of pre-ozonation on mitigation of ceramic UF membrane fouling caused by algal extracellular organic matters," Chem. Eng. J., vol. 294, pp. 157-166, 2016.

[9] W. Neubrand, S. Vogler, M. Ernst, and M. Jekel, "Lab and pilot scale investigations on membrane fouling during the ultra fi Itration of surface water $\boldsymbol{s}^{2}$, " Desalination, vol. 250, no. 3, pp. 968-972, 2010.

[10] H. Huang, T. Young, and J. G. Jacangelo, "Novel approach for the analysis of bench-scale, low pressure membrane fouling in water treatment," J. Memb. Sci., vol. 334, no. 1-2, pp. 1-8, 2009.

[11] J. G. Jacangelo, "Low Pressure Membrane Filtration of Natural Waters : Principles and Methodology," Environ. Sci. Technol. vol. 42, no. 3, pp. 714-720, 2008.

[12] A. H. Nguyen, J. E. Tobiason, and K. J. Howe, "Fouling indices for low pressure hollow fiber membrane performance assessment.," Water Res., vol. 45, no. 8, pp. 262737, 2011.

[13] M. Zupančič, D. Novak, J. Diaci, and I. Golobič, "An evaluation of industrial ultrafiltration systems for surface water using fouling indices as a performance indicator," Desalination, vol. 344, pp. 321-328, 2014.

[14] W. Yu, Y. Yang, and N. Graham, "Evaluation of ferrate as a coagulant aid/oxidant pretreatment for mitigating submerged ultrafiltration membrane fouling in drinking water treatment," Chem. Eng. J., vol. 298, pp. 234-242, 2016.

[15] F. Qu, X. Du, B. Liu, J. He, N. Ren, G. Li, and H. Liang, "Control of ultrafiltration membrane fouling caused by Microcystis cells with permanganate preoxidation: 
Significance of in situ formed manganese dioxide," Chem. Eng. J., vol. 279, pp. 56-65, 2015.

[16] R. S. Juang, C. Huang, and C. L. Hsieh, "Surface modification of PVDF ultrafiltration membranes by remote argon/methane gas mixture plasma for fouling reduction," J. Taiwan Inst. Chem. Eng., vol. 45, no. 5, pp. 2176-2186, 2014.

[17] E. J. Lee, Y. H. Kim, C. H. Lee, H. S. Kim, and H. S. Kim, "Effect of different physical conditions on fouling control in in-situ chemical cleaning in place (CIP) for flat sheet membranes fouled by secondary effluents," Chem. Eng. J., vol. 302, pp. 128-136, 2016.

[18] J. Tian, M. Ernst, F. Cui, and M. Jekel, "Effect of different cations on UF membrane fouling by NOM fractions," Chem. Eng. J., vol. 223, pp. 547-555, 2013.

[19] S. L. Low, S. L. Ong, and H. Y. Ng, "Characterization of membrane fouling in submerged ceramic membrane photobioreactors fed with effluent from membrane bioreactors," Chem. Eng. J., vol. 290, pp. 91-102, 2016.

[20] J. Kwak, B. Khang, E. Kim, and H. Kim, "Estimation of Biochemical Oxygen Demand Based on Dissolved Organic Carbon, UV Absorption, and Fluorescence Measurements," J. Chem., vol. 2013, pp. 1-9, 2013.

[21] A. Matilainen, E. T. Gjessing, T. Lahtinen, L. Hed, A. Bhatnagar, and M. Sillanpää, "An overview of the methods used in the characterisation of natural organic matter (NOM) in relation to drinking water treatment.," Chemosphere, vol. 83, no. 11, pp. 1431-42, 2011.

[22] N. Her, G. Amy, D. McKnight, J. Sohn, and Y. Yoon, "Characterization of DOM as a function of MW by fluorescence EEM and HPLC-SEC using UVA, DOC, and fluorescence detection.," Water Res., vol. 37, no. 17, pp. 4295-303, 2003.

[23] P. Xiao, F. Xiao, D. Wang, T. Qin, and S. He, "Investigation of organic foulants behavior on hollow-fiber UF membranes in a drinking water treatment plant," Sep. Purif. Technol., vol. 95, pp. 109-117, 2012.

[24] S. A. Huber, A. Balz, M. Abert, and W. Pronk, "Characterisation of aquatic humic and non-humic matter with size-exclusion chromatography - organic carbon detection organic nitrogen detection (LC-OCD-OND)," Water Res., vol. 45, no. 2, pp. 879-885, 2011.

[25] J. E. Birdwell and A. S. Engel, "Characterization of dissolved organic matter in cave and spring waters using UV-Vis absorbance and fluorescence spectroscopy," Org. Geochem., vol. 41, no. 3, pp. 270-280, 2010.

[26] Z. Ye, H. Zhang, X. Zhang, and D. Zhou, "Treatment of landfill leachate using electrochemically assisted UV/chlorine process: Effect of operating conditions, molecular weight distribution and fluorescence EEM-PARAFAC analysis," Chem. Eng. J., vol. 286, pp. 508-516, 2016. 
[27] Y. Shutova, A. Baker, J. Bridgeman, and R. K. Henderson, "Spectroscopic characterization of dissolved organic matter changes in drinking water treatment: From PARAFAC analysis to online monitoring wavelengths," Water Res., vol. 54, pp. 159-169, 2014.

[28] K. R. Murphy, C. A. Stedmon, and R. Bro, "Chemometric analysis of organic matter fluorescence," in Aquatic Organic Matter Fluorescence, eds P.Coble, J.Lead, A.Baker, D.Reynolds, and R. G. M. Spencer (Cambridge, UK: Cambridge University Press), 339-375

[29] R. Bro and M. Vidal, "EEMizer: Automated modeling of fluorescence EEM data," Chemom. Intell. Lab. Syst., vol. 106, no. 1, pp. 86-92, 2011.

[30] W.-T. Li, J. Jin, Q. Li, C.-F. Wu, H. Lu, Q. Zhou, and A.-M. Li, “Developing LED UV fluorescence sensors for online monitoring DOM and predicting DBPs formation potential during water treatment," Water Res., vol. 93, pp. 1-9, 2016.

[31] R. H. Peiris, C. Hallé, H. Budman, C. Moresoli, S. Peldszus, P. M. Huck, and R. L. Legge, "Identifying fouling events in a membrane-based drinking water treatment process using principal component analysis of fluorescence excitation-emission matrices.," Water Res., vol. 44, no. 1, pp. 185-94, 2010.

[32] S. Peldszus, C. Hallé, R. H. Peiris, M. Hamouda, X. Jin, R. L. Legge, H. Budman, C. Moresoli, and P. M. Huck, "Reversible and irreversible low-pressure membrane foulants in drinking water treatment: Identification by principal component analysis of fluorescence EEM and mitigation by biofiltration pretreatment.," Water Res., vol. 45, no. 16, pp. 5161-70, 2011.

[33] R. H. Peiris, M. Jaklewicz, H. Budman, R. L. Legge, and C. Moresoli, “Assessing the role of feed water constituents in irreversible membrane fouling of pilot-scale ultrafiltration drinking water treatment systems.," Water Res., vol. 47, no. 10, pp. 336474, 2013.

[34] F. Chen, S. Peldszus, R. H. Peiris, A. S. Ruhl, R. Mehrez, M. Jekel, R. L. Legge, and P. M. Huck, "Pilot-scale investigation of drinking water ultrafiltration membrane fouling rates using advanced data analysis techniques.," Water Res., vol. 48, pp. 508-18, 2014.

[35] S. Shao, H. Liang, F. Qu, H. Yu, K. Li, and G. Li, "Fluorescent natural organic matter fractions responsible for ultrafiltration membrane fouling: Identification by adsorption pretreatment coupled with parallel factor analysis of excitation-emission matrices," J. Memb. Sci., vol. 464, pp. 33-42, 2014.

[36] C. A. Andersson and R. Bro, "The N -way Toolbox for MATLAB," Chemom. Intell. Lab. Syst., vol. 52, pp. 3-6, 2000.

[37] C. M. Andersen and R. Bro, "Review Practical aspects of PARAFAC modeling of Fluorescence excitation-emission data," J. Chemometrics, vol. 17, pp. 200-215, 2003. 
[38] F. Lu, C. H. Chang, D. J. Lee, P. J. He, L. M. Shao, and A. Su, "Dissolved organic matter with multi-peak fluorophores in landfill leachate," Chemosphere, vol. 74, no. 4, pp. 575-582, 2009.

[39] W. Chen, P. Westerhoff, J. a Leenheer, and K. Booksh, "Fluorescence excitation Emission matrix regional integration to quantify spectra for dissolved organic matter," Environ. Sci. Technol., vol. 37, no. 24, pp. 5701-5710, 2003.

[40] Y.-J. Kim, T. Yun, S. Lee, D. Kim, and J. Kim, "Accelerated testing for fouling of microfiltration membranes using model foulants," Desalination, vol. 343, pp. 113-119, 2014.

[41] D. Jermann, W. Pronk, S. Meylan, and M. Boller, "Interplay of different NOM fouling mechanisms during ultrafiltration for drinking water production.," Water Res., vol. 41, no. 8, pp. 1713-22, 2007.

[42] L. Ao, W. Liu, L. Zhao, and X. Wang, "Membrane fouling in ultrafiltration of natural water after pretreatment to different extents," J. Environ. Sci., vol. 43, pp. 234243, 2016. 